\title{
Project Oficinas Design
}

\author{
Glaucinei Corrêa $^{1, a}$, Karine Moura ${ }^{2}$, Wilton Pereira ${ }^{3}$, Cayano Sarvel ${ }^{4}$ and Jameny Sarmiento ${ }^{5}$ \\ ${ }^{1}$ Universidade Federal de Minas Gerais, Depto TAU, Rua Paraíba, 697 - Funcionários - 30.130-140 - Belo Horizonte/MG - Brasil \\ 2, 3, 4, 5 Universidade Federal de Minas Gerais, students, Rua Paraiba, 697 - Funcionários - 30.130-140 - Belo Horizonte/MG - Brasil
}

\begin{abstract}
This article presents the experiment and obtained results of the Project Oficinas Design, showing the social-economic inclusion of artisans by thematic workshops that allied design with popular art, seeking development/improvement of the artisan products. These workshops aimed development/perfecting of craftwork products, adding value and making possible an increase on the generated financial income. The methodological procedures used included an active participation of researchers, professors, students, technicians and artisans on the conception, cooperation and integration of methods and instruments during the execution of the project. The activities were orientated by dialogic relations based on: proximity between the subjects, respect and mutual recognizing. The steps of the project development were: (1) Preparing the students for the community work and (2) Researching and studying groups and institutions from all over the world that do this type of work; (3) Preparing didactic material to be used on the workshops; (4) Workshops with weekly encounters with the artisans; (5) Disclosing of obtained results with the program. It is possible to conclude that the project achieved most of its goals. Also, the development of the project activities allowed the integration between society and university, promoting academic learning for the students.
\end{abstract}

Keywords. design, craftwork, social inclusion.

\section{Introduction}

The extension Program CASOS: catadores de sonhos", from the Design course of the Architecture School of the Universidade Federal de Minas Gerais (UFMG), promotes social-economics inclusion of waste pickers and artisans with two projects: "Projeto Design Reciclado" (Recycled Design Project) and "Projeto Oficinas design" (Design Workshop Project).

This article shows specifically the Project Oficinas Design which has as main objective showing artisans how to craft products with cultural identity by design notions.

The artisan group, named "Oficinário", is composed by 30 women from Belo Horizonte that reunited looking for disclosure and selling of its products.

Another objective of this project is to promote the integration between society and academy, contributing to the intellectual and social formation of the scholarship students involved by showing the history and reality of the artisan's lives.

Another goal of Project Oficinas Design was to promote the independence of artisans from the project, so the group could not rely on University actions only. Because of this, the Action-Research was used as focus

\footnotetext{
${ }^{a}$ Corresponding author: glaucinei@ufmg.br
}

for the planning and construction of parts of the acts. From Thiollent (1986), it is a social research with empirical basis that is designed and realized with an strict association with an action or the solving of a problem in common and in which the researchers and participants are involved in a cooperative or participative manner.

The starting point for the Project Oficinas Design was to respond the artisans necessity of developing its projects and turning them into more attractive ones by design, which is an area that is always involved with characteristics that have to attend to a series of factors relating to necessity of users and market, which means responding to social, economic, productive, ambiental, symbolic, among with other aspects. (CORRÊA and CASTRO, 2013).

In that manner, the project activities worked in harmony with the "Oficinário" group, the pedagogic project of the Design course and the development planning of the UFMG. 


\section{Theoretical framework}

The relation used in the project activities was based on the proximity of subjects, a dialogic relation relied on mutual recognizing and respect. Researchers, professors, students, artisans and members of the community exchanged knowledge and discovering. The project breaker the common relation in which the teacher/master is the only one responsible for teaching and the student for learning. It became a multilateral learning process.

In this project, the learning concept of Lave and Packer (2008) was used. This means that everyone is in a constant learning process, independently of the location for that to occur.

According to Lave and Wenger (1991), every time we think about learning, the first thought considered is the relationship master-apprentice. However, in practice, the roles of the master are surprisingly variable in time and space, and the relationship master-apprentice is not a defining characteristic of learning.

From that principle, looking to describe how the design intervention happened - in the product development, professional training and workshops fragments of texts from authors that studied the design influence on popular art were used. This became fundamental for the development of this project.

Nemer (2003) discussed the matter of listening the artisan: "The craftwork is the result of the human hand and the keeper of its complex culture. It is important to get to know the embroiderer artisan and listen to her, creating paths to emerge what she considers an icon.[...] The correct intervention consists in, many times, helping her to perfect what she does, but always respecting its essence" (own translation).

Borges (2006) stated about the respect that needs to exist on the moment of the intervention: "When we do not respect the artisan, I'm convinced that it is better to leave it alone than intervene without caution, with pretension. The hazardous potential of a badly concluded intervention is high and its effects are very harmful" (own translation).

Barroso (1999), questions the mischaracterization of the product: "How to intervene in the product and crafting process without losing its characteristics and valuing and reinforcing its regional traditions, the artisan's ability and the existing relations inside the focused groups" (own translation).

These citations reflect the importance attributed to the activities realized in the project. The respect and valuing for the culture of the groups/institutions involved, in this case, for the artisans of the Oficinário Group, composed the basis for the work developed. If it did not, the results would be compromised and unfinished.

The goal was to make the people involved find out the value that could be inserted in the product they were developing/creating. Aiming that, taking experimentation, testing, and crafting in consideration was essential.

\section{Methodological Procedures}

The initial contact with the artisan's group happened by the INSEA ${ }^{1}$ institution, responsible for giving support to waste pickers and recycler's associations. After getting to know them and understand their demands, the group started the development of the themes and content of the project's workshops, that were created aiming the knowledge and discovering exchange between researchers, professors, students, technicians and artisans.

In that perspective, activities related to the goals established for the Project Oficinas Design were proposed and are detailed in the following paragraphs.

The two first steps were developed cooperatively, preparing the students for the work to be developed, establishing manners to interact with the group and get to know what and how the artisans craft: (1) Prepare the students for the community work and (2) Research and study groups and institutions from all over the world that do this type of work

While the research was in progress, weekly meetings were made to promote discussions about the texts that were selected for being related to the activities in progress. Weekly, a student was assigned to make a presentation that should contain: a) a short summary and structure of the article; b) an author's biography; c) most important topics; d) reflections on the matters that related to the project; e) references utilized on the article. The presentations transformed the weekly meetings into more dynamic ones and also taught all the participants more about the authors and subjects researched.

In that phase, many important meetings occurred, providing moments of identification and approximation between the artisans of the Oficinário Group and the Project's team. On those, the artisans answered specific questions that served as basis to think and plan the following step workshops.

Aiming to study and evaluate the crafted products, a presentation of the work was solicited to the artisans on the first meetings. This made possible getting to know better every one of them and their works. Starting from the explaining of the production methods, to the exposing of their desires and difficulties related to production and commercializing of the products.

\footnotetext{
Non-governmental organization focused on technical advice to community groups, companies and NGOs, especially with recyclable material and street population collectors, in the creation and development of environmental management models. More information: www.insea.org.br.
} 


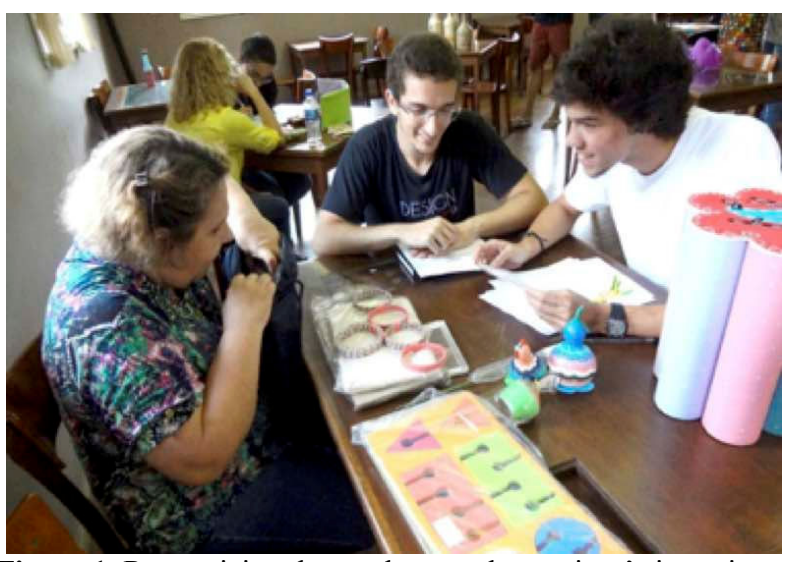

Figure 1. Recognizing the products and an artisan's interviews.

On that moment, the crafted products were analyzed to identify ways to classify the type of craftwork of the group. According to Barroso (2003), the craftwork can be separated in: popular art, native, traditional, conceptual, of cultural reference, typical products and domestic.

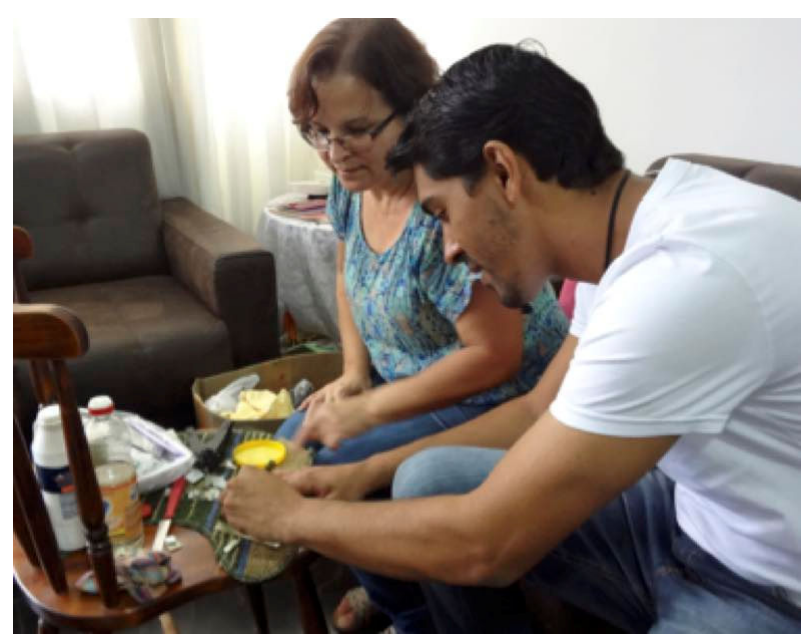

Figure 2. Visiting an artisan's house.

Also on the initial phase, visits to artisan's houses/offices were planned looking for an even closer relation, getting to know the work and routine seeking potentials and difficulties identification, especially those related to the producing of the craftwork.

The step (3), Prepare didactic material, consisted on developing all the material to be used on the workshops. The interviews and visits realized on the previous step helped to elaborate what would be the participant's profiles, which were fundamental to define the thematic axis of the workshops.

A total of 10 workshops were defined, with the duration of 3 hours per each. The themes chosen were: 1) design and craftwork definition; 2) color and form studies; 3) behavior tendencies; 4) identity; 5) creativity; 6) market; 7) product lines; 8) product development; 9) costing; 10) communication.

Every didactic material used on the workshops was made by scholarship students, under supervision of the coordinator, that had to study the subjects, organize and synthetize every content discussed, proposing activities and exercises to help on the theme's comprehension.

This material was composed of slide presentations that helped on the theoretical workshops, complementing material, that were a printed summary of the workshop's content, and the given exercises for content fixation.

The next step (4), Workshops, occurred for the period of 17 months, from May of 2015 to 2016's December, with weekly meetings with the artisans.

The final step (5), Disclosure of the results (processes and products developed) achieved with the program that it is still in progress, consists on article writing, final event preparing and book confectioning, in which all the process, methodology adopted in the project and obtained results will be disclosed.

\section{Workshop's Development}

Seventeen artisans participated on the project. Seven of them had a degree, eight of the rest finished high school, the other 2 have not got into high school whatsoever. This heterogeneity showed, already, how challenging it would be to deepen into the workshop contents with the whole group.

The craftwork developed by this group can be classified as domestic, connected to manualities with few or none evident aspect of cultural reference, where the craftwork activity was, almost always, said to be an alternate source of income (69\%), that given the fact that the majority of the group had more than 60 years old and were retired.

The plurality of the group was easily noted on the necessities and desires as it was also perceived on limitations that related to many aspects, such as time availability, previous knowledge on the subjects and schooling level. On the following text, one can find the detailing of the workshops.

Workshop 1 - Design and Craftwork definition: Contextualize Design and Craftwork, relate both as its cultural values. This workshop was divided into 2 meetings, the first one focusing design.

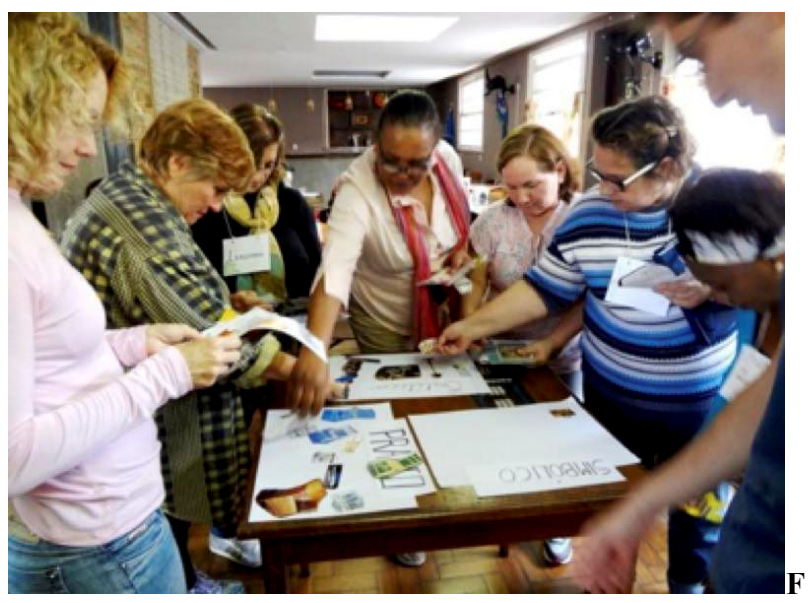

igure 3. Artisans classifying their products.

On the second encounter, with craftwork as main subject, a discussion started with a question: what was everyone's concept of craftwork. Following that, each 
artisan spoke for a moment telling how its own learning or perfecting process is done. After this, identity and Minas Gerais's craftwork was discussed. To finish and exemplify all the craftwork types and its differences, a dynamic was realized in which all the participants could classify different objects according to the concepts: decorative, utilitarian, ludic, liturgic or conceptual.

Workshop 2 - Color and form studies: discuss color's application on the everyday, how colors can influence people, especially in huge companies marketing ideas.

On the dynamic proposed for this workshop, primary colors were used. The participants had to mix and create its own colors, and, after that, paint an A3 sized sheet with the preferred one. After drying, cooperatively, the group made a chromatic scale on the floor, classifying the colors in hot or cold.

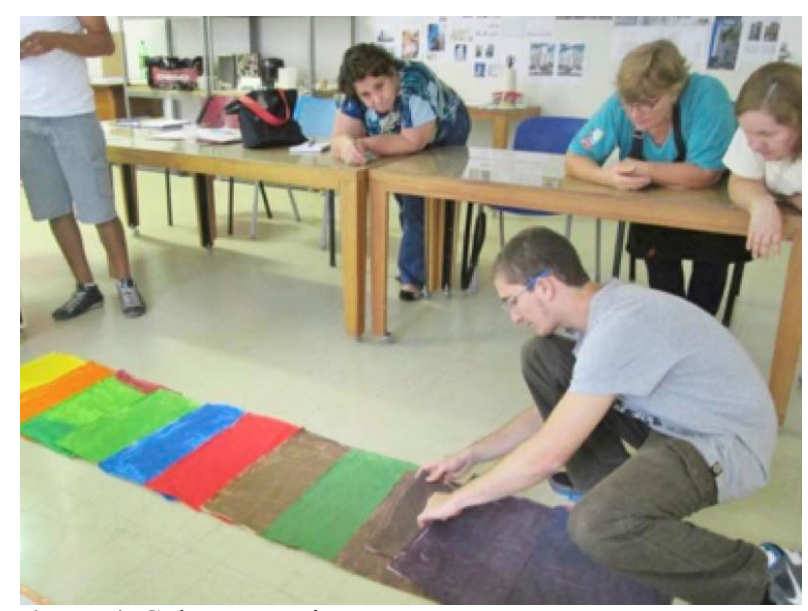

Figure 4. Color Dynamic.

To exemplify the chromatic circle, an A4 gridded sheet was used, in which the participants, utilizing different painting colors, had to make, each one, its chromatic circle. During the activity, the scholarship students explained the goal of the activity and the expected results.

Workshop 3 - Behavior tendencies: put on evidence how the cultural, economic and technologic changes interfere in the way of life. The workshop initiated with a conversation about behavior and its interference in product evolution. As example, photographs of products that shows clearly a formal and conceptual alteration, according to time, following the behavior changes and people's necessity were used.

Different styles from a variety of groups were used, such as: The Boom Makers: influence by its popularity; The Manu: collective that guides a certain group of people; The Leafs: Adheres for a cause or style; The Catchers: potential captivators; The Followers: unite to a vary of movements, The Seeds: mix its identity to a movement.

To finish this workshop, the last question discussed was the reason why this was discussed, and why it could be useful. The importance of keeping aware to the surrounding, to what people desire to change, to always observe new opportunities to develop new products focusing the customer, was highlighted.

Workshop 4 - Identity: reinforce the symbolic aspect of craftwork, as the subjects related to iconography and to culture. This workshop, considered one of the most important ones, began with a dialogue about the definition of identity, using as example fingerprints. Do fingerprints define a person? What makes people different? With that being discussed, the group came to the common sense that characteristics, existence, experience and culture is what defines the identity of each person. Many exercises were used to unroll the subject.

Workshop 5 - Creativity: techniques of creativity. Different creative profiles and the influence of the environment on the product creation. This guided the creativity workshop, that started with a question: what comes to the mind when creativity is discussed? A person? A place? Or an experience?

Workshop 6 - Market: this workshop started with the competitiveness subject, reinforcing the fact that, to be competitive, focusing in adding value and not diminishing the product price is necessary. From that, the discussion was guided by the question: Where can this essential value be found? This conversation was very productive and served to emphasize the importance of the symbolic in artisan products.

On the following encounter, competition was the main theme. A delicate subject, especially when working with a group that acts directly on the same market. Looking for a more formal approach, the method of competition analysis was shown: strength, opportunities, weaknesses and threats. This method was used applying the tool in its context. The results were interesting, considering the necessity to visualize and analyze the whole scenario, getting to know deeply all of its potentials as everything and everyone that acts in this business environment.

Finally, the Mix and Marketing concepts were introduced, composing the 4 P's of the Marketing, showing its applications by the use of examples and the importance of each one.

Workshop 7 - Product Lines: from this workshop, onwards, a more objective approach was used, directioned to the craftwork, specifically. The goal was to apply the concepts already studied on the previous workshops. The focus was to show how a product or an identity can act with success in a line with different applications.

As the objective was to make a very practical workshop, an activity where the product concept should contain the Architecture School (where all the workshops occurred) was given. An initial orientation was given to put in evidence many ways to recognize, in a specific subject, and apply, in a product, the iconography. It is the act of identifying and reuniting visual elements that contain the imaginary of people in their lives and all over their history. 


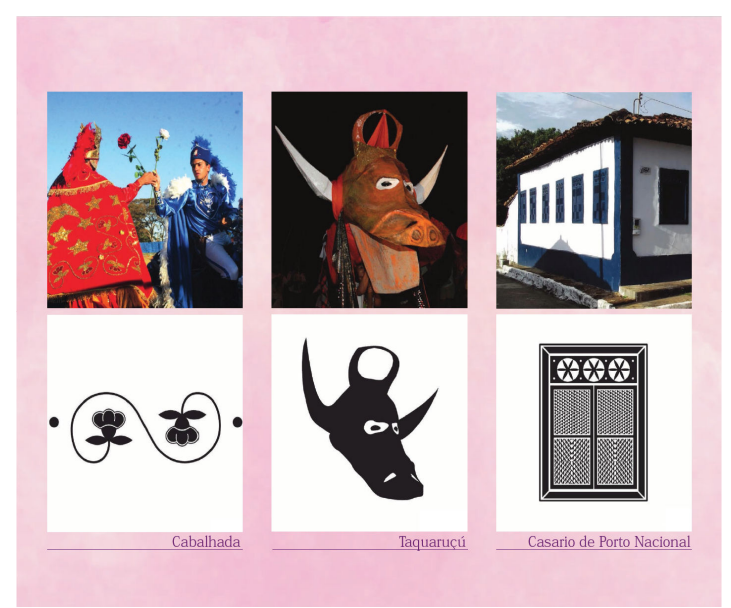

Figure 5. Part of the Iconography slides.

Workshop 8 - Product Development: considered the main workshop, the participants were motivated to analyze the notes taken on the last workshop and, from them, produce fast sketches that were verified and reworked to produce patterns, repetitions or icons, very used in printery, and could, in the future, become used in their own products.

The artisans were led to adjust the product concept to a specific public, in this case, the Architecture School of UFMG. The products would supposedly, be sold on a upcoming fair. In that way, the challenge was established to promote the mix of knowledge and techniques obtained on the workshops and to make the participants think on factors that connects cultural identity, experience, habits and traditions to significantly changes on the product.

Also, the group had to think on subjects related to the market, identifying opportunities from this specific profile, taking in consideration its characteristics, necessities, desires and financial capability.

The goal was to develop products thinking on a line made of, at least, 3 pieces, using the following steps: Understanding, Observing, Defining, Idealizing, Prototyping and Testing.

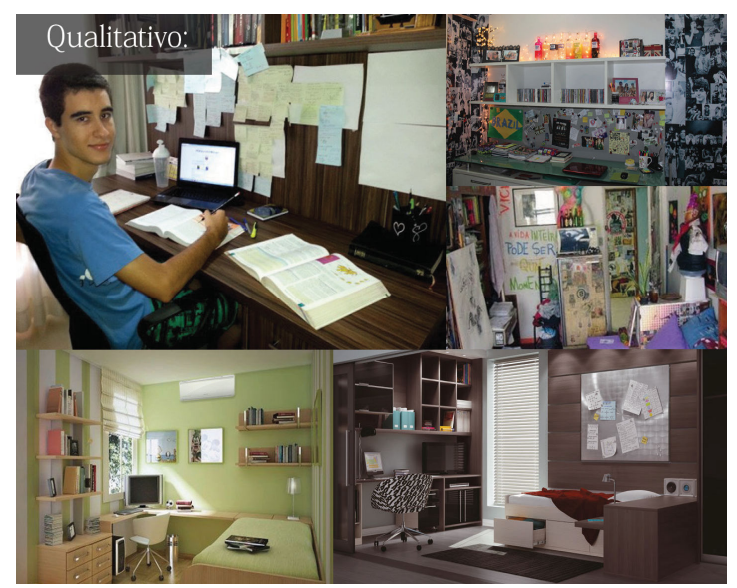

Figure 6. Customer's profile Moodboard.

On the idealizing step, the participants made a brainstorming session, which provided insights that came with drawings of possible alternatives of products. In an creating and relaxation environment, the artisans could walk freely on the room observing different photographs of the school, fixed on a panel, looking to, from them, get more insights that could generate esthetic attributes and/or visuals of products.

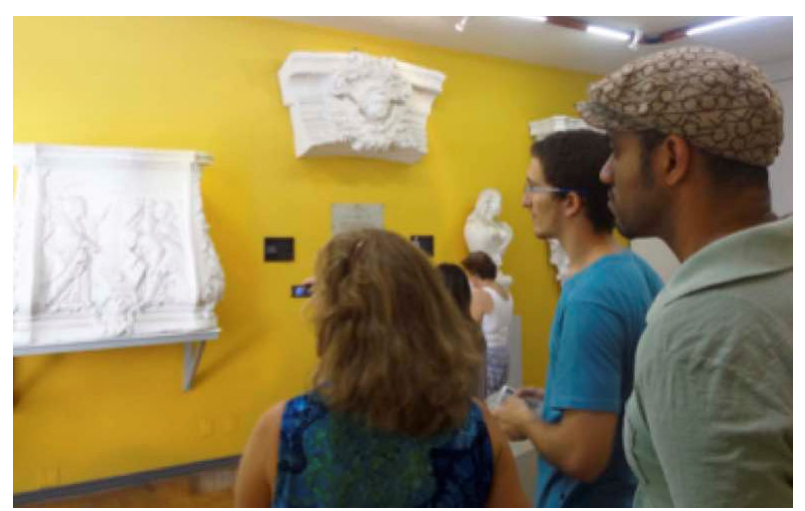

Figure 7. Reference collecting on a school visit.

The artisans had then the challenge of giving form to the main ideas, bringing them to the tridimensional space. Some prototypes were developed from paper or alternative materials, looking to clarify the dimensions and physical appearance of the product. All the time, participants were stimulated to generate alternatives and to test them without previous judgments or prejudice, which means, none alternative was discarded, even though it could appear weird, the main idea was to always look for a possibility.

Workshop 9-Costing: it is a subject that artisans are not used to work with, and for that reason, they tend to neglect the math involved in the pricing process, especially for not knowing how to register and measure the time spent on the producing of their products.

The participants had to map everything involved in costs and pricing of the produced products. For example: how much does it cost to buy the material used on the product, how much time was spent in every piece of the product and what profit margin is taken in every product. This and other information are very relevant to price correctly the products

Workshop 10 - Communication: the brand that is presented in every place in which the products and the artisans are is its identity represented in a graphic form or not. That being said, the workshop was initiated summarizing all the subjects already discussed, with main focusing on identity and product line, putting in evidence that this subject has been discussed from the first workshop onwards.

Many case examples and others, of different themes, were exposed as references. Some classifications that brands could get were shown as many other examples.

The workshop continued with different methods of brand disclosing (social media and other digital forms), visiting cards, as a more interactive way, tags, bags and many other ways.

\section{Results}

After the last workshop, the scholarship students had meetings with every one of the artisans, to accompany 
and orientate them in product development. On those meetings, besides the accompanying, the students aimed to reinforce the content seen on all 10 workshops.

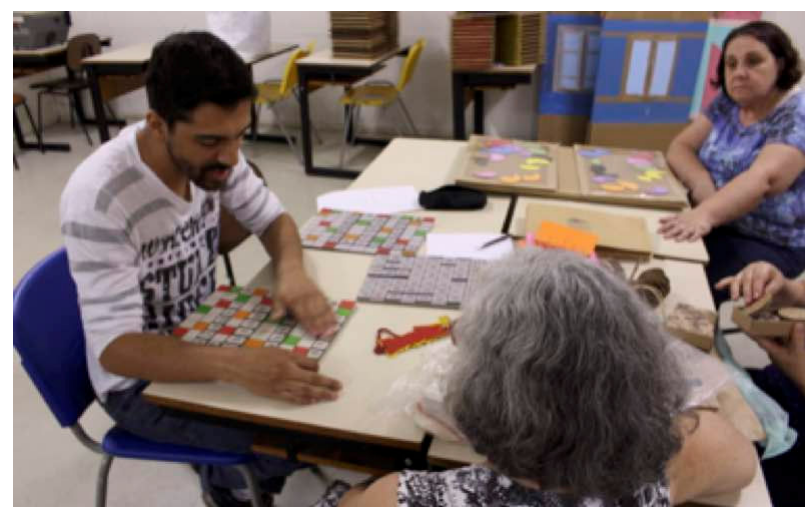

Figure 8: Meetings of students and artisans for orienting.

Following that, a date was set to all the artisans to show their products, having as reference everything discussed and learned previously, on the project activities.

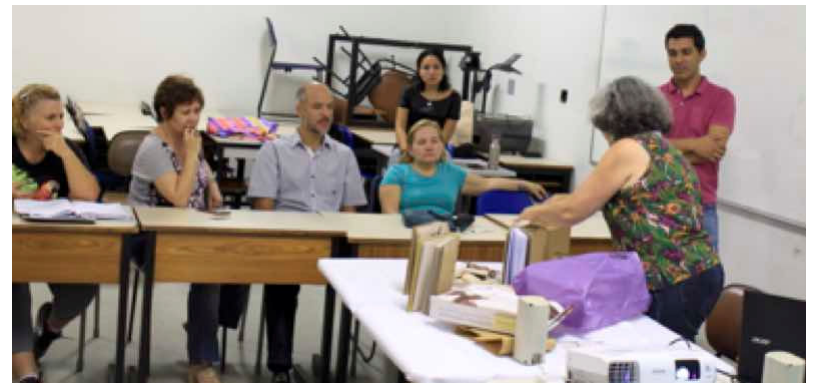

Figure 9: Artisan's products presentation.

\section{Final considerations}

In a general idea, it is possible to conclude that every goal of the project was achieved. The Project Oficinas Design finished on December of 2016, with the artisans showing their own developed products from all the knowledge obtained with the project workshops.

As the objective of the project was to create autonomy for the artisans, and that requires time, in this case, of at least 2 years, considering that as the project development time, the hardest challenge was to keep the interest of the artisans. That being said, from 17 starting members of the group, only 8 had concluded all the activities.

From the beginning, the evasion was expected, taking in consideration the profile of all the artisans from the initial group, the extensive duration of the project, as the difficulties in maintaining the purpose of generating autonomy of the participants.

Analyzing everything that was done from the beginning of the project - student preparing, artisans involvement, preparing and applying of the workshops; accompanying the product development - it is possible to state that, by the means of design, a contribution in other's lives happened, being that an increase in life quality of the involved with the relations or even with the products, in which technic and practical development can be noticed.

Concluding, as examples of positive results of the project, artisans stated that participating on the project was very important, because it made their first contact with design methods and projects, which they would never get to know if they were not members of this group, and, as result, they have now a new perception of everything that surrounds them in the artisan environment.

\section{Acknowledgments}

Our acknowledgment is directed to MEC/SESu, for the financial support for the project.

A special acknowledgment for the Pró-reitoria de Extensão (PROEX) of Universidade Federal de Minas Gerais (UFMG), for the support and motivation through the entire of the project.

\section{References}

ARRUDA, Marcos. Situando a economia solidária. In: Economia Solidária: desafios para um novo tempo. Fundação Luís Eduardo Magalhães. Salvador: FLEM, 2003. 132p (Cadernos FLEM, 5), p. 1932.

BARROSO NETO, Eduardo. Design, Identidade, Cultura e Artesanato. Primeira Jornada Iberoamericana de Design no Artesanato, 1999.

BORGES, Adélia. A intervenção do design no produto de artesanato. In: Seminário Artesanato: intervenções e mercados (caminhos possíveis). Centro de Negócios de São Paulo, 25 de outubro de 2006. São Paulo: Artesanato Solidário/Artesol e SEBRAE, 2006.

CORRÊA, Glaucinei Rodrigues; CASTRO, Maria Luiza A. C. O pensamento complexo de Edgar Morin e o design. Revista Estudos em Design (online). Rio de Janeiro, v 21, n 1, p 115, 2013.

LAVE, Jean; PACKER, Martin. Towards a social ontology of learning. In: NIELSEN, K. et al. A qualitative stance: essays in honor of steinar Kvale. Oxford: Aarhus Universitetsforlag, 2008.

LAVE, Jean; WENGER; Etienne. Situated learning: legitimate peripheral participation. New York: Cambridge University Press, 1991.

NEMER, J. A. Palestra no VII Encontro Design e Artesanato do Museu A CASA. In: A Casa: museu do objeto brasileiro, 2003.

(http://www.acasa.org.br/ensaio.php?id=46\&modo=pain el)

THIOLLENT, Michel. Metodologia da Pesquisa-Ação. São Paulo: Cortez, 1986. 